\title{
Human and feline adipose-derived mesenchymal stem cells have comparable phenotype, immunomodulatory functions, and transcriptome
}

Kaitlin C. Clark' , Fernando A. Fierro ${ }^{2}$, Emily Mills Ko ${ }^{1}$, Naomi J. Walker ${ }^{1}$, Boaz Arzi ${ }^{3}$, Clifford G. Tepper ${ }^{4}$, Heather Dahlenburg ${ }^{2}$, Andrew Cicchetto ${ }^{2}$, Amir Kol ${ }^{1}$, Lyndsey Marsh'1, William J. Murphy ${ }^{5}$, Nasim Fazel ${ }^{5}$ and Dori L. Borjesson ${ }^{1 *}$

\begin{abstract}
Background: Adipose-derived mesenchymal stem cells (ASCs) are a promising cell therapy to treat inflammatory and immune-mediated diseases. Development of appropriate pre-clinical animal models is critical to determine safety and attain early efficacy data for the most promising therapeutic candidates. Naturally occurring diseases in cats already serve as valuable models to inform human clinical trials in oncologic, cardiovascular, and genetic diseases. The objective of this study was to complete a comprehensive side-by-side comparison of human and feline ASCs, with an emphasis on their immunomodulatory capacity and transcriptome.

Methods: Human and feline ASCs were evaluated for phenotype, immunomodulatory profile, and transcriptome. Additionally, transwells were used to determine the role of cell-cell contact in ASC-mediated inhibition of lymphocyte proliferation in both humans and cats.

Results: Similar to human ASCs, feline ASCs were highly proliferative at low passages and fit the minimal criteria of multipotent stem cells including a compatible surface protein phenotype, osteogenic capacity, and normal karyotype. Like ASCs from all species, feline ASCs inhibited mitogen-activated lymphocyte proliferation in vitro, with or without direct ASC-lymphocyte contact. Feline ASCs mimic human ASCs in their mediator secretion pattern, including prostaglandin E2, indoleamine 2,3 dioxygenase, transforming growth factor beta, and interleukin-6, all augmented by interferon gamma secretion by lymphocytes. The transcriptome of three unactivated feline ASC lines were highly similar. Functional analysis of the most highly expressed genes highlighted processes including: 1) the regulation of apoptosis; 2) cell adhesion; 3) response to oxidative stress; and 4) regulation of cell differentiation. Finally, feline ASCs had a similar gene expression profile to noninduced human ASCs.

Conclusions: Findings suggest that feline ASCs modulate lymphocyte proliferation using soluble mediators that mirror the human ASC secretion pattern. Uninduced feline ASCs have similar gene expression profiles to uninduced human ASCs, as revealed by transcriptome analysis. These data will help inform clinical trials using cats with naturally occurring diseases as surrogate models for human clinical trials in the regenerative medicine arena.
\end{abstract}

Keywords: Multipotent adult progenitor cell, Mesenchymal stem cell, Adipose tissue, Feline, Human, Animal model, Immunomodulation

\footnotetext{
* Correspondence: dlborjesson@ucdavis.edu

'Veterinary Institute for Regenerative Cures and Department of Pathology,

Microbiology and Immunology, University of California, Davis, CA 95816, USA

Full list of author information is available at the end of the article
} 


\section{Background}

Mesenchymal (multipotent) stem cells (MSCs) are proliferative, plastic adherent, fibroblast-like stromal cells that can be isolated from many tissue types [1]. Adipose tissue is an important tissue source for MSC expansion (ASCs) [2]. Fat collection is relatively noninvasive, the frequency of MSCs in fat is about 10-fold higher than in bone marrow, and fat is more readily available in small animals, older animals, and people. In comparative studies, ASCs appear to be highly enriched in immune-related genes and may have advantages in terms of proliferation, stability, and immunomodulatory ability, perhaps as a result of their retaining the metabolic and inflammatory modulating transcriptome native to its tissue [3-7].

Immunomodulation by MSCs represents a novel therapeutic option for various inflammatory and immunemediated diseases $[2,8,9]$. MSCs modulate cell activation, differentiation, and secretion of almost all cells of the innate and humoral immune systems. MSCs inhibit T-cell proliferation with an associated decrease in tumor necrosis factor (TNF) $\alpha$ secretion in humans, rodents, and veterinary species including horses and dogs [8-10]. Human, equine, and canine ASCs secrete soluble mediators that are known to be immunomodulatory, including prostaglandin E2 ( $\left.\mathrm{PGE}_{2}\right)$, indoleamine 2,3 dioxygenase (IDO), interleukin (IL)-6, IL-8, transforming growth factor (TGF) $\beta$, and vascular endothelial growth factor (VEGF) [6, 7, 11-14]. Human MSCs and ASCs also regulate T-cell and B-cell function via direct cell-cell interaction [15-17]. The increased recognition of the role of MSCs in immunomodulation, combined with successes in phase I-III clinical trials in humans using stem cell therapy for inflammatory and immune-mediated diseases, has resulted in recommendations that immune functional assays be developed as potency-release criteria for advanced-phase clinical trials [18].

Naturally occurring diseases in companion animals are increasingly recognized for the important role they play in discovery about human diseases and translational medicine [19]. These diseases in companion animals may better reflect the complex genetic, environmental, and physiological variations present in human diseases compared to induced diseases in laboratory animals [20]. Clinical trials in academic veterinary medicine mirror that of human healthcare systems, and animal owners are eager to enroll in these trials [20]. The selection of appropriate large animal models for preclinical testing in human stem cell trials should rely on solid comparative studies, as MSCs from rodents may or may not recapitulate the immunomodulatory profile of human MSCs. For example, there are important differences between human and murine MSC secretion profiles that may dictate how predictive mouse models are for studies that focus on
MSCs and innate immune cells, $\mathrm{CD}^{+} \mathrm{T}$ cells, and mechanism-of-action studies [9, 21-23].

Companion animals can serve as relevant, preclinical, surrogate, translational models for MSC therapy and contribute directly to investigational new drug applications for human clinical trials. Cats with naturally occurring diseases analogous to human conditions can provide insight into feasibility, safety, and biologic activity of novel stem cell therapies. The development of appropriate and relevant large animal models will: 1) reduce the work needed when translating pre-clinical data to human trials; and 2) assist in choosing human trials to pursue. Naturally occurring diseases in cats can help determine the ideal route of cell administration, cell dose, the number of cell doses, and efficacy readouts to optimize the potential for successful human clinical trials. Cats develop a variety of spontaneous inflammatory and immune-mediated diseases, and stem cell therapy trials are already underway for chronic oral mucosa inflammation [24], asthma [25], and chronic enteropathy [26]. For example, feline chronic gingivostomatitis has a similar T-cell activation phenotype to the human oral inflammatory diseases oral lichen planus, apthous stomatitis, and pemphigus vulgaris [27, 28]. Cats also serve as valuable models for noninflammatory diseases, including chronic renal failure [29, 30].

The objectives of this work were to delineate a comprehensive immunomodulatory profile of feline ASCs and to perform a direct side-by-side comparison of feline and human ASCs as a first step in determining how ASCs from this relevant large animal species compare to human ASCs. We found that cat ASCs largely mimic human ASCs in basic phenotype, early proliferative ability, transcriptome, secretion profile (notably IDO and $\mathrm{PGE}_{2}$ ), and functional downregulation of activated T-cell proliferation.

\section{Methods}

\section{Tissue samples}

Human adipose tissue was obtained as discarded material from female patients undergoing a breast reduction procedure in compliance with an approved protocol $(n=5$; University of California, Davis (UCD) Institutional Research Board, protocol number 258314-8). For all human tissues collected, informed patient consent forms were obtained. Subcutaneous feline adipose tissue was surgically obtained from specific pathogen-free (SPF) cats $(n=3)$ and from client-owned cats $(n=3)$ undergoing routine surgery. Fat collection was conducted according to a protocol approved by the Institutional Animal Care and Use Committee, and the Clinical Trials Review Board, UCD (protocol number 18422). All owners of clientowned cats signed an informed consent form. All cats 
were free of feline immune deficiency virus and feline leukemia virus infection.

\section{Human ASC isolation and expansion}

Adipose tissue ( $20 \mathrm{~g}$ ) was mixed with $10 \mathrm{~mL}$ phosphatebuffered saline (PBS) and homogenized (gentleMACS dissociator; Miltenyi Biotec, San Diego, CA, USA). Samples were centrifuged at $1500 \mathrm{rpm}$ for $5 \mathrm{~min}$ and the cell/tissue pellet was incubated with $10 \mathrm{~mL}$ animal origin-free collagenase (CLSAFA, $267 \mathrm{U} / \mathrm{mL}$; Worthington Biochemical, Lakewood, NJ, USA) for 30 mins with gentle agitation at $37{ }^{\circ} \mathrm{C}$. Samples were centrifuged at $2000 \mathrm{rpm}$ for $7 \mathrm{~min}$ and cell pellets were resuspended and plated at 1000 cells $/ \mathrm{cm}^{2}$ in plastic culture flasks using standard culture medium (minimum essential medium (MEM) $\alpha$; GE Healthcare Life Sciences HyClone Laboratories, Logan, UT, USA) supplemented with $10 \%$ fetal bovine serum (FBS; Atlanta Biologicals, Flowery Branch, GA, USA), 1\% L-glutamine, and 1\% penicillin/streptomycin (ThermoFisher Scientific, Gibco, Pittsburgh, PA, USA). After 2 days, nonadherent cells were removed by washing twice with PBS. MSCs from passages 3-5 were used for experimentation.

\section{Feline ASC isolation and expansion}

ASCs were isolated from fat and cultured as previously described [24]. ASCs from passages 3-5 were used for experimentation.

\section{ASC morphology and size}

Adherent feline and human ASCs were imaged on a phase-contrast microscope using bright field. To quantify cell sizes, images were taken of five random areas of two human and two feline ASC lines grown in T225 flasks. Twenty cells from each image were measured using ImageJ software.

Comparison of cell size in suspension of human $(n=2)$ and feline $(n=2)$ ASCs was assessed by flow cytometry. Human ASCs were labeled using CD105 conjugated with APC (BD Biosciences, Pharmingen, San Jose, CA, USA) and feline ASCs were labeled using CD90 conjugated with PE (Leukocyte Antigen Biology Laboratory, UCD, clone CA1.4G8) as previously described [24, 31]. Labeled human and feline lines were mixed 1:1 and read on a flow cytometer (Cytomics FC500; Beckman Coulter, Brea, CA, USA). Cell size of fluorochrome-labeled human and feline cells was determined by forward and side scatter.

\section{Karyotype}

Feline $(n=2$, passage 5$)$ and human $(n=2$, passage 4$)$ ASCs were karyotyped as previously described [32]. ASCs were plated in a six-well plate, treated with colcemid (ThermoFisher Scientific) to arrest the mitotic cells in metaphase, lifted and prepared with serial washes and fixations for staining and microscopic analysis. Analysis included scanning all slides, counting a minimum of 20 metaphases, analysis of a minimum of seven metaphases, and karyotyping a minimum of two metaphases.

\section{ASC surface phenotype}

Human and feline ASCs ( $n=5$ each) were incubated for 45 min with fluorophore-conjugated antibodies including CD44, CD45 (human ASCs), CD18 (feline ASCs), CD90, CD105, and MHCII as previously described [24, 31]. All human antibodies were purchased from BD Biosciences and feline antibodies were purchased from the Leukocyte Antigen Biology Laboratory, UCD, unless otherwise indicated (MHC II (clone 42.3), CD18 (clone FE3.9 F2), CD90 (clone CA1.4G8), CD44 (clone IM7; BioLegend, San Diego, CA, USA), and CD105 (SN6; eBioscience, SanDiego, CA, USA). Mouse IgG-APC (MCA928; AbD Serotec, Kidlington, Oxford, UK) was used as an isotype control. All samples were run on a flow cytometer (Cytomics FC500). Flow cytometry data were analyzed using FlowJo flow cytometry software (Tree Star, Ashland, OR, USA).

\section{Osteogenesis}

Osteogenic assays were performed as previously described $[33,34]$. In brief, $10,000 \mathrm{ASCs} / \mathrm{cm}^{2}$ were cultured for 14 days with media changes every 3 days $(n=2$ human ASCs and $n=2$ feline ASCs). Osteogenic medium consisted of standard culture medium supplemented with $0.2 \mathrm{mM}$ ascorbic acid (Sigma-Aldrich, St. Louis, MO, USA), $0.1 \mu \mathrm{M}$ dexamethasone (Sigma-Aldrich), and $20 \mathrm{mM} \beta$-glycerolphosphate. Cells were fixed with $10 \%$ $\mathrm{vol} / \mathrm{vol}$ formalin solution for $15 \mathrm{~min}$, washed once with PBS, and stained for $20 \mathrm{~min}$ with 1\% wt/vol Alizarin Red S (ARS, Ricca Chemical Company, Arlington, TX, USA) with gentle shaking to stain for precipitated calcium (Sigma-Aldrich). Samples were then photographed.

\section{ASC proliferation}

ASCs ( $n=4$ human, $n=5$ feline) were plated into two T25 flasks at 5000 cells $/ \mathrm{cm}^{2}$. At each passage, ASC viability was determined (trypan blue exclusion dye; ThermoFisher Scientific) and ASCs were enumerated (by hemocytometer). ASCs were passaged at $70-80 \%$ confluence. In order to normalize differences in when cells were passaged, population doubling times were calculated as previously described [35]. Cultures were terminated at passage 6 .

\section{Lymphocyte suppression assay (LSA)}

LSAs were run, with and without a transwell, to compare the ability of feline and human ASCs to inhibit activated T-cell proliferation and to determine if $\mathrm{T}$ cellASC contact is necessary for inhibition of lymphocyte proliferation ( $n=5$ feline and $n=5$ human lines). Our 
goal was to maximally stimulate human and feline T-cell proliferation using mitogens. Previous work in our laboratory in horses [14], dogs, and cats (unpublished data) demonstrated that allogenic peripheral blood mononuclear cells (PBMCs) only weakly and variably stimulate T-cell proliferation. Our pilot data demonstrated, in agreement with others, that concanavalin $\mathrm{A}(\mathrm{ConA})$ is the best and most potent mitogen for mature, circulating, post-thymic cells in cats (unpublished data and [36-38]) whereas leucoagglutinin (PHA) is the best T-cell mitogen for human T lymphocytes $[39,40]$.

Feline PBMC isolation and LSAs were carried out as previously described $[14,24]$. In brief, PBMCs were isolated from whole blood using gradient centrifugation and were co-incubated with irradiated ASCs in culture wells at a 1:5 (PBMC:ASC) ratio and activated with $5 \mathrm{mg} / \mathrm{mL}$ ConA (Sigma-Aldrich). Cells were co-cultured for 4 days. Control wells included PBMCs alone, ASCs alone, ConA-stimulated PBMCs, and PBMCs mixed with ASCs without ConA stimulation. To determine the role of contact, cells were plated in transwell dishes (Corning $0.4 \mu \mathrm{M}$ polycarbonate membrane 24 -well plate; Corning, NY, USA) with PBMCs in the bottom and ASCs in the insert. To determine IDO activity, the experiment was run as described; however, media were supplemented with L-tryptophan (Sigma-Aldrich) to a final concentration of $600 \mu \mathrm{M}$.

For human LSAs, PBMCs were isolated using FicollPaque (GE Healthcare) according to the manufacturer's instructions and MSC-PBMC co-incubation, with and without transwells, was performed as previously described for feline LSAs except the medium used was $\alpha$ MEM (GE Healthcare Life Sciences) with 16\% FBS (Atlanta Biologicals), $1 \%$ penicillin/streptomycin (ThermoFisher Scientific), and 1\% Glutamax (ThermoFisher Scientific), and the PBMCs were stimulated with PHA (SigmaAldrich; $2.5 \mu \mathrm{g} / \mathrm{ml})[39,40]$.

Human and feline PBMC proliferation was measured via 5-bromo-29-deoxyuridine (BrdU) incorporation (BrdU Flow Kit; BD Biosciences) and analyzed on a flow cytometer (Cytomics FC500). Flow cytometry data were analyzed using FlowJo flow cytometry software (Tree Star).

\section{Mediator secretion (ELISA)}

Feline and human $\mathrm{PGE}_{2}$, TGF $\beta 1$, VEGF, interferon (IFN) $\gamma$, TNF $\alpha$, IL-6, IL-8, and IL-10 were measured in LSA supernatants in duplicate using enzyme-linked immunosorbent assay (ELISA) kits following the manufacturer's instructions. Feline analytes were measured with feline-specific kits (IFN $\gamma$, TNF $\alpha$, IL-6, IL-8, and IL-10: Duosets; R\&D Systems, Minneapolis, MN, USA) or feline-validated kits (TGF $\beta 1$ : multispecies TGF- $\beta 1$ (ThermoFisher Scientific) [41]; VEGF: human QuantiKine Kit (R\&D) [42, 43]; and $\mathrm{PGE}_{2}$ : competitive ELISA (Enzo Life Sciences,
Farmingdale, NY, USA) [44, 45]). Human TGF $\beta 1$, VEGF, IFN $\gamma$, TNF $\alpha$ (QuantiKine), $\mathrm{PGE}_{2}$, (competitive ELISA kit), IL-6, IL-8, and IL-10 (DuoSets) were all purchased from R\&D. All ELISA samples were read on a Synergy HTMulti-Mode microplate reader with Gen5 software (Biotek, Winooski, VT, USA).

\section{IDO assay}

IDO catalyzes the conversion of tryptophan to $\mathrm{N}$-formyl kynurenine, which is then catabolized to kynurenine. Kynurenine levels are directly proportional to IDO activity. Two volumes of LSA media (that had been supplemented with tryptophan) were treated with 1 volume of $30 \%$ trichloroacetic acid (Sigma-Adrich) and centrifuged. Equal parts of trichloroacetic acid-treated supernatant and Ehrlich's reagent (1\% $p$-dimethylaminobenzaldehyde in glacial acetic acid; Sigma-Aldrich) were mixed and read at $490 \mathrm{~nm}$ on a microplate reader (Synergy HT Multi-Mode Gen5 software) [14].

\section{RNA isolation}

Total RNA was isolated from three primary feline ASC cultures using the RNeasy Mini Kit (Qiagen, Inc., Valencia, CA, USA). RNA quantity and quality were assessed on a NanoDrop spectrophotometer (Thermo Scientific) and the Agilent 2100 Bioanalyzer (Agilent Technologies, Santa Clara, CA, USA), respectively.

\section{RNA-Seq library preparation and next-generation sequencing (NGS)}

Whole transcriptome profiling was performed using a directional, strand-specific mRNA-Seq approach for three feline ASC lines. Briefly, total RNA samples were submitted to the UC Davis Comprehensive Cancer Center's Genomics Shared Resource (GSR), and indexed RNA-Seq libraries were prepared from 200 ng total RNA using the KAPA Stranded mRNA-Seq Kit (Kapa Biosystems, Inc., Wilmington, MA, USA) according to the manufacturer's standard protocol. Poly-adenylated mRNA was purified from total RNA and ribosomal RNA removed by binding to oligo (dT) beads, which was followed by RNA fragmentation by incubation at $94{ }^{\circ} \mathrm{C}$ in the presence of magnesium. Double-stranded cDNA was then generated by random-primed first-strand synthesis and subsequent second-strand synthesis in the presence of dUTP for strand marking. The double-stranded cDNA was then 3'A tailed and indexed, Illumina-compatible adapters were ligated. The libraries were then enriched by high-fidelity PCR amplification (15 cycles) with KAPA HiFi HotStart DNA Polymerase and adapter-specific primers. Subsequently, libraries were combined for multiplex sequencing on an Illumina HiSeq 4000 System (100-bp, paired-end; $\sim 30$ million reads/sample) [46]. 


\section{Next generation sequencing data analysis}

Image processing, base calling, quality scoring (Phred), and sample demultiplexing were executed by HiSeq Control Software with Real Time Analysis (HCS v3.3.41/ RTA 2.5.2) and bcl2fastq Conversion Software (Illumina; San Diego, CA, USA). FASTQ-formatted sequence data were analyzed using a standard HISAT (hierarchical indexing for spliced alignment of transcripts)-Cufflinks workflow. RNA-Seq sequence reads (FASTQ format) were aligned to the reference cat genome assembly (Nov. 2014, ICGSC Felis Catus 8.0) using HISAT software [47]. Gene- and transcript-level expression were comprehensively quantified with Cufflinks software [48], which performed: 1) transcript assembly; 2) identification of splice variants; 3) quantification of expression as FPKM (fragments per kilobase of transcript per million mapped reads) values; and 4) normalization. Normalized FPKM values (Cuffnorm output) were utilized for downstream analysis steps. Statistical analyses and hierarchical clustering of the data were performed with GeneSpring GX software (Agilent Technologies, Inc.), and geneannotation enrichment analysis performed with tools available from the Database for Annotation, Visualization and Integrated Discovery (DAVID v6.7) $[49,50]$.

Meta-analysis of the feline ASC expression data was performed with RNA-Seq data for human ASCs (NCBI GEO Accession GSE37521) [51]. For this, gene expression values from both datasets (feline ASCs: FPKM; human ASCs: RPKM (Reads Per Kilobase of transcript per Million mapped reads)) were separately normalized (quantile), joined on similar Gene IDs, and then baseline-transformed. Values for replicate samples were averaged and, subsequently, hierarchical clustering (similarity measure: Euclidean; linkage rule: centroid) was performed on the genes exhibiting variance across the human ASC cell types ( $\geq 2$-fold change relative to undifferentiated ASCs).

\section{Statistical analyses}

For all cell-based assays, normal distribution of the data was tested using the Kolmogorov and Smirnov test. For normally distributed data, a one sample Student's $t$ test (normalized data; lymphocyte proliferation) or paired $t$ test (non-normalized data) or analysis of variance (ANOVA; $>2$ comparisons) was used. For feline nonnormally distributed data, a Mann-Whitney-Wilcoxon test was used to determine differences in protein secretion data. Human data were analyzed using Wilcoxon matched pairs test. Human inflammatory mediators were normalized to paired lymphocyte donors before analysis was performed. Commercially available statistical software was used for all statistical analyses (GraphPad InStat version 3.06 for Windows; GraphPad, La Jolla, CA, USA). Results are presented as mean and standard error. A $P$ value of $<0.05$ was considered statistically significant.

\section{Results \\ Human and feline ASCs are morphologically and phenotypically similar}

The ASCs derived from feline and human adipose tissue had typical spindle-shaped, adherent morphology (Fig. 1a and b). However, human ASCs were significantly larger, both when adhered to plastic and when in suspension, than feline ASCs (adherent cells, $p<0.001$, Fig. 1c; suspended ASCs, Fig. 1d). Both feline and human ASCs had a normal metaphase spread and karyotype (Additional file 1: Figure S1). The surface protein expression on feline and human ASCs was compared using markers that define MSCs [1]. Both feline and human ASCs were strongly positive for CD44, CD90, and CD105, and were negative for leukocyte markers (CD18 (feline) and CD45 (human)), and MHCII (Fig. 1e and f) [31, 52, 53]. Both feline and human ASCs were capable of osteogenic differentiation (Fig. $1 \mathrm{~g}$ and $\mathrm{h}$ ). Others have established the full trilineage differentiation capacity of feline ASCs, including chondrogenic and adipogenic differentiation [52, 54-57]. Together, these data suggest that feline ASCs are karyotypically normal, meet the minimal criteria of multipotent stem cells and are smaller but otherwise morphologically and phenotypically identical to human ASCs.

\section{Human and feline ASCs are highly proliferative and inhibit allogeneic mitogen activated T-cell proliferation} Human and feline ASCs readily proliferated in culture with comparable doubling times from passages 3-6 (clinically relevant passage numbers; Fig. 2a). Previous data from our laboratory and others has demonstrated a significant slowing of feline ASC proliferation after passage $5[31,52]$. Human and feline ASCs significantly reduced activated T-cell proliferation $(P<0.004$ all conditions compared to positive control; Fig. $2 \mathrm{~b}$ and $\mathrm{c}$ ). This inhibition occurred with or without ASC-T cell contact. However, human ASCs, when in direct contact with activated $\mathrm{T}$ cells, more potently reduced activated $\mathrm{T}$-cell proliferation as compared to human ASCs plated in transwells ( $P=0.03$; Fig. $2 \mathrm{c})$. These findings suggest that feline ASCs, like other species, are potent modulators of activated $\mathrm{T}$-cell proliferation and that this modulation is largely mediated by secreted factors. Interestingly, human ASCs also markedly decrease activated T-cell proliferation, but this regulation is stronger when ASCs are in direct contact with $\mathrm{T}$ cells.

\section{Activated human and feline ASCS secrete high concentrations of immunomodulatory mediators}

ASCs function in large part via the secretion of mediators that regulate cells of the cellular and humoral immune 
a

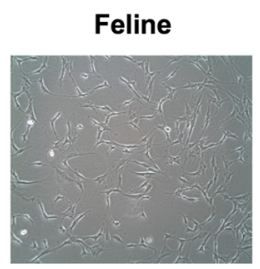

C

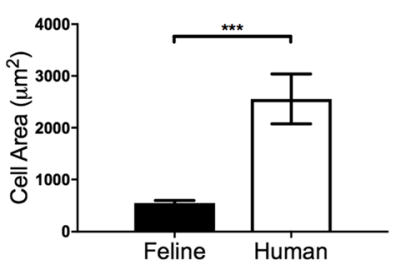

e

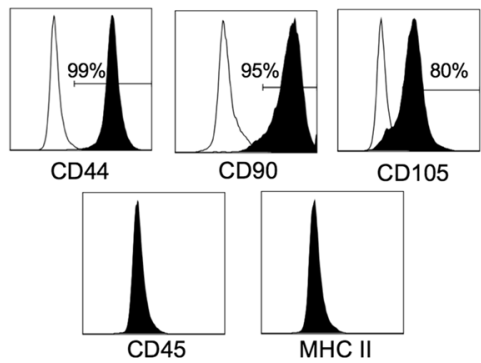

g

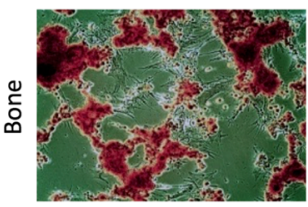

b

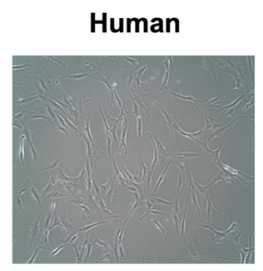

d

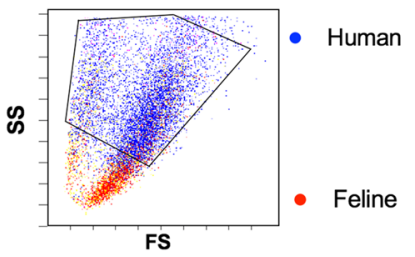

f Human

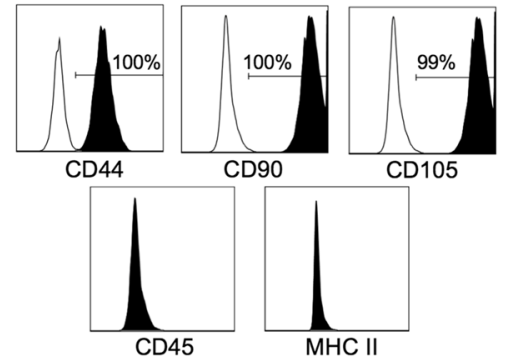

h

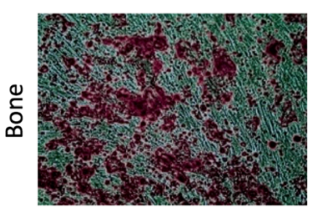

Fig. 1 Human and feline ASCs possess typical MSC characteristics. Feline (a) and human (b) ASCs adhere to plastic and have a spindle, fibroblast morphology in culture. However, human ASCs are significantly larger than feline ASCs when adherent (c) and in suspension (d). Feline (e) and human (f) ASCs both have positive surface expression of CD44, CD90, and CD105, and are negative for surface expression of CD45 (pan leukocyte, human) or CD18 (pan leukocyte, feline) and MHC II. Both feline (g) and human (h) ASCs undergo osteogenic differentiation. Cell size presented as mean and standard error. ${ }^{*} P<0.05,{ }^{* *} P<0.01,{ }^{* * *} P<0.001$

system. We measured a number of mediators implicated in the immunomodulatory function of ASCs in parallel feline and human assays, with and without activation, and with or without cell-cell contact, to define feline ASCs and dissect out similarities and dissimilarities between cat and human ASCs. ASCs of both species variably secrete very low concentrations of IDO, $\mathrm{PGE}_{2}$, IL-6, and VEGF at baseline in culture, or in the context of allogeneic PBMCs; however, ASCs in the context of mitogen-activated T cells secrete significantly higher concentrations of immunomodulatory mediators. Activated feline ASCs secreted high concentrations of IDO (Fig. 3a), similar to canine and human MSCs (Fig. 3b) but unlike murine MSCs [21]. Activated feline ASCs also secrete high concentrations of $\mathrm{PGE}_{2}$ (Fig. 3c) that, unlike human ASCs (Fig. 3d), is significantly augmented by ASC-T cell contact. Activated feline and human ASCs secrete high concentrations of IL6 (Fig. 3e and f) and VEGF (Fig. $3 g$ and h), with or without MSC-T cell contact. Human ASC secretion of VEGF was not enhanced by T-cell activation (Fig. 3h).

We measured two mediators, IL- 8 and TGF $\beta$, that are potentially secreted by both activated PBMCs and ASCs (Fig. 4). For both feline and human cells, more IL-8 is present in activated ASC-PBMC co-cultures than is present in cultures with ASCs alone (Fig. $4 \mathrm{a}$ and b; $P=0.08)$ regardless of cell-cell contact. Cell-cell contact significantly increased IL-8 secretion for human cultures $(P<0.05)$ but not for feline cultures $(P=0.12)$. Feline TGF $\beta$ secretion mimicked our findings for human ASCs. Regardless of species, TGF $\beta$ was secreted by activated PBMCs, by ASCs at baseline, and in the context of ASCPBMC co-incubation, with or without activation and with 

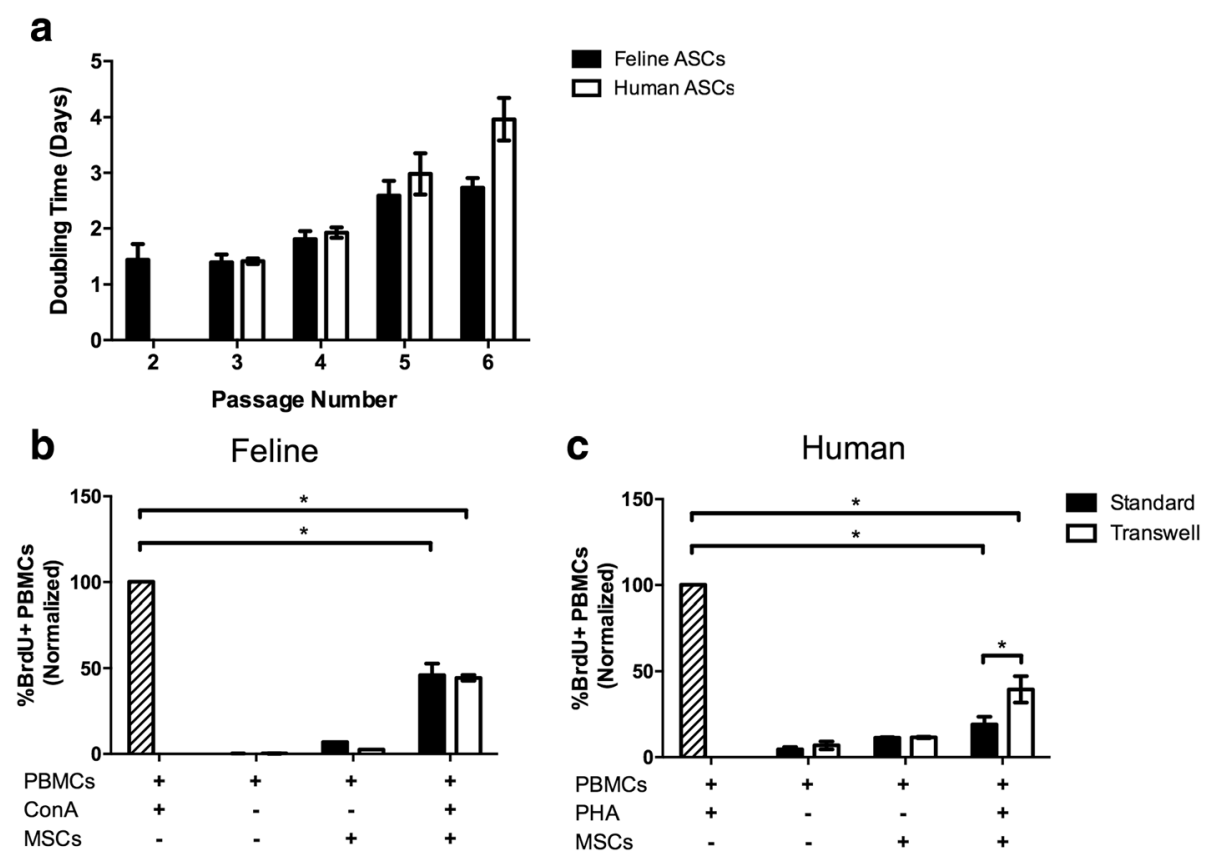

Fig. 2 Human and feline adipose-derived mesenchymal stem cells (ASCS) display similar proliferative capacity and immune-suppressive functions. Doubling times were calculated for feline ASCs at passages 2-6 and for human ASCs at passages 3-6. The proliferation rate of human and feline ASCs is comparable throughout multiple passages (a). Feline ASCs co-incubated with stimulated peripheral blood mononuclear cells (PBMCS) suppress lymphocyte proliferation regardless of direct contact (transwells) (b). Human ASCs similarly inhibit leucoagglutinin (PHA)-induced lymphocyte proliferation; however, direct contact with stimulated PBMCs leads to stronger inhibition than the transwell condition (c). Data presented as mean and standard error. ${ }^{*} P<0.05,{ }^{* *} P<0.01,{ }^{* *} P<0.001$. BrdU 5-bromo-29-deoxyuridine, ConA concanavalin A, MSC mesenchymal stem cell

or without contact (Fig. 4c and d). The concentrations varied between conditions; however, there was no condition which significantly altered TGF $\beta$ secretion.

Findings agree with previous data from horses, humans, and dogs in which TGF $\beta$ is constitutively secreted and not, by definition, upregulated by activation [14, 58, 59].

Activation of PBMCs results in the secretion of IFN $\gamma$, TNF $\alpha$, and IL-10; however, neither feline nor human ASCs, even in the context of allogenic PBMCs, secreted these mediators (Fig. 5). Typically, the inhibition of lymphocyte proliferation is associated with decreased IFN $\gamma$ and TNF $\alpha$ production and variable IL-10 secretion. Unlike human ASCs, feline ASCs only inhibited IFNY secretion in the absence of direct MSC-T cell contact whereas, when ASCs were in contact with $\mathrm{T}$ cells, IFNy was not inhibited. Conversely, human ASCs were capable of inhibiting IFN $\gamma$ secretion when ASCs and T cells were in direct contact; however, in the absence of contact, ASCs were not able to inhibit IFNy (Fig. 5a and b). Both feline and human ASCs inhibited TNF $\alpha$ secretion; however, feline ASCs were more able to inhibit TNF $\alpha$, like IFN $\gamma$, when ASCs were not in direct contact with T cells (Fig. 5c and d). Activated feline ASCs did increase PBMC secretion of IL-10; however, activated human
ASCs did not alter IL-10 secretion regardless of cell-cell contact (Fig. 5e and f).

Transcriptome analysis of feline ASCs demonstrates their relatedness and insight into their biological properties

Having defined and compared the biological features of feline ASCs, transcriptome analysis was next performed in order to evaluate the relatedness of the feline ASCs to each other, as well as to human ASCs, and to gain insight into the functional implications of the ASC gene expression profile (full dataset in Additional file 2: Figure S2; available at NCBI GEO Datasets Accession number: GSE94773. Pair-wise correlation analyses of the genelevel expression data (i.e., FPKM) for each ASC culture demonstrated that there was a high level of similarity between the ASC preparations isolated from the three cats (Pearson $r=0.853,0.891$, and 0.974) (Fig. 6a). There was a significant overlap of genes (2743 genes, 89.00$90.47 \%)$ that exhibited at least a moderate level of expression (i.e., $\geq 15$ FPKM) in each ASC preparation. Significant overlap of gene expression profiles from the three feline ASC lines was highly expressed in 401 genes ( $\geq 100$ FPKM; Fig. $6 b$ ). In order to gain insight into the functional significance of the ASC expression repertoire, functional annotation analysis was performed on the 
a

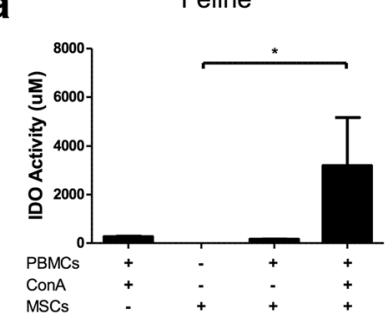

C

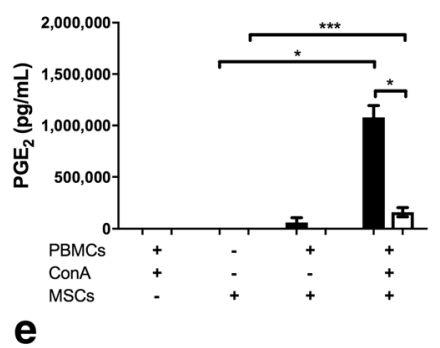

e

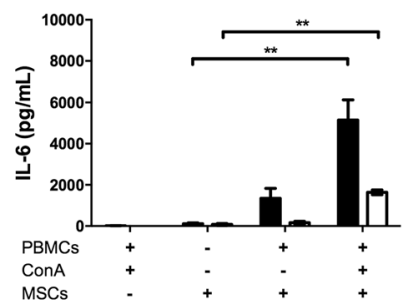

g

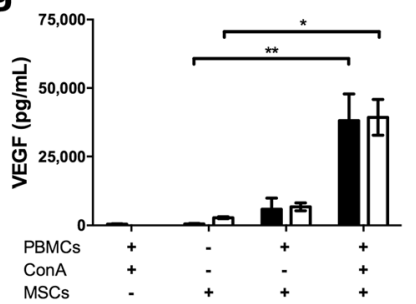

b

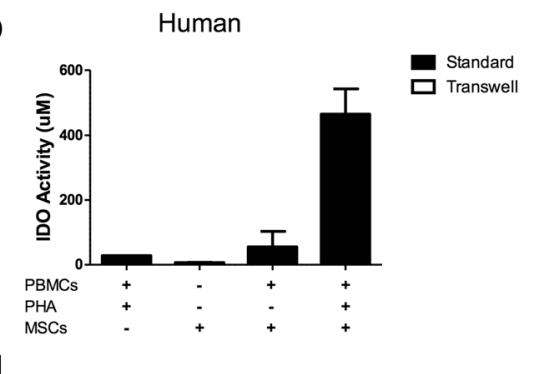

d
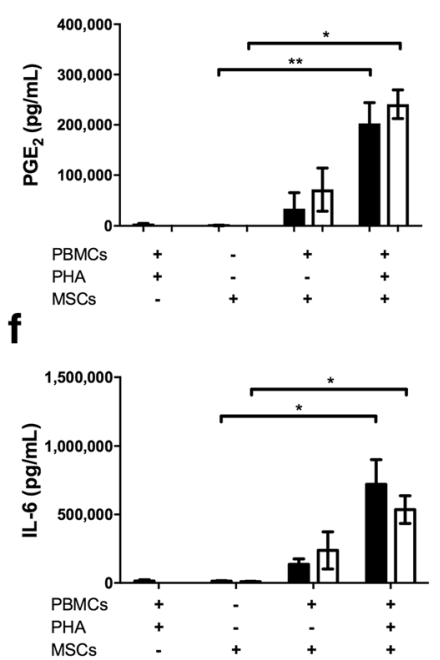

h

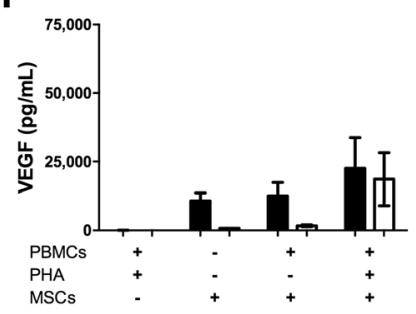

Fig. 3 Human and feline ASCs produce immunomodulatory mediators. Feline ASCs in the presence of proliferating peripheral blood mononuclear cells (PBMCs) increase indoleamine 2,3 dioxygenase (IDO) activity (a). Increased IDO activity was observed by stimulated human ASCs, but was not statistically significant $(\mathbf{b})$. Production of prostaglandin $\mathrm{E}_{2}\left(P G E_{2}\right)$ occurred in both standard and transwell conditions in cats; however, greater production occurred when feline ASCs were in direct contact with stimulated PBMCs (c). Human ASCs produce PGE 2 to the same magnitude with or without contact to stimulated PBMCs (d). Interleukin-6 (IL-6) was significantly upregulated regardless of contact for both feline (e) and human (f) ASC co-cultures. Feline ASCS produced vascular endothelial growth factor (VEGF) in standard and transwell conditions in cats (g). However, VEGF was not significantly increased above baseline by stimulated human ASCs (h). Data presented as mean and standard error. ${ }^{*} P<0.05,{ }^{* *} P<0.01,{ }^{* * *} P<0.001$.

ConA concanavalin A, MSC mesenchymal stem cell, PHA leucoagglutinin

most highly expressed genes (i.e., $\geq 100$ FPKM; 401 genes) that were common to all ASCs, with the notion that this would highlight the most prominent processes. For this, the gene set was analyzed with tools available from DAVID Bioinformatics Resources 6.7 that evaluate gene-gene functional relationships and enrichment for biological "modules" [49, 50]. There was overrepresentation of gene ontology categories involved in a number of processes, including: 1) the regulation of apoptosis; 2) cell adhesion; 3) response to oxidative stress; 4) regulation of cell differentiation; and 5) various metabolic processes, including phosphate metabolism, sterol metabolism, and oxidative phosphorylation (Fig. 6c).

Finally, the potential similarity of feline ASCs to their human counterparts was investigated by performing meta-analysis with an RNA-Seq dataset from human ASCs that were either undifferentiated (noninduced) or induced to differentiate along the adipogenic, osteogenic, and chondrogenic lineages (NCBI GEO Accession GSE37521; Fig. 7) [51]. Genes exhibiting variance across the human ASC cell types ( $\geq 2$-fold change relative to 

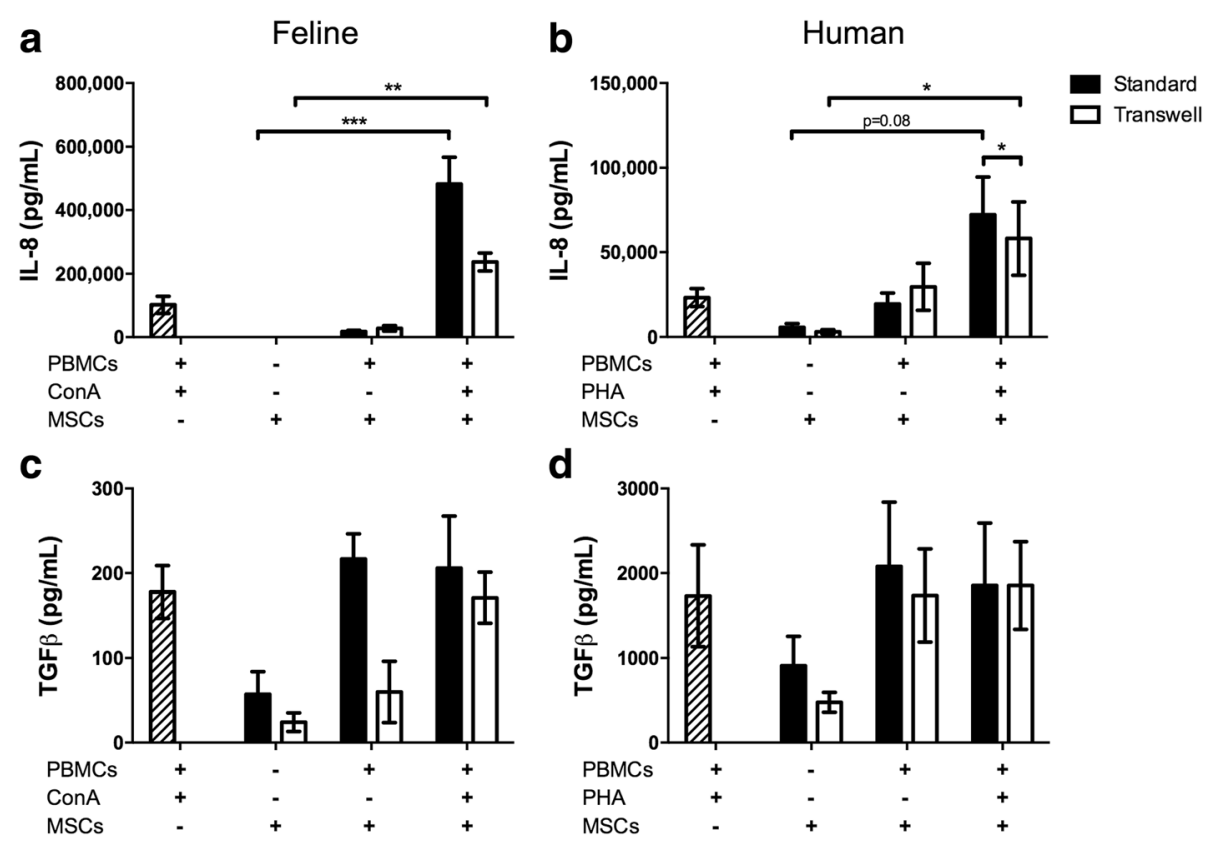

Fig. 4 Human and feline ASCs increase interleukin-8 (IL-8) but not transforming growth factor beta (TGF $\beta$ ) above baseline peripheral blood mononuclear cell (PBMC) production. Production of IL-8 by feline ASCs is significantly increased regardless of contact with stimulated PMBCs (a). IL-8 is also produced by stimulated human ASCs with $(P=0.08)$ and without contact $(\mathbf{b})$. Production of TGF $\beta$ by activated mesenchymal stem cells (MSCs) is not altered from baseline expression regardless of contact in both cats (c) and humans (d). Data presented as mean and standard error. ${ }^{*} P<0.05,{ }^{* *} P<0.01,{ }^{* * *} P<0.001$. ConA concanavalin A, PHA leucoagglutinin

undifferentiated ASCs) were determined and then used as the basis for hierarchical clustering with the feline ASCs. The feline ASCs clustered closely and were intermingled with the undifferentiated human ASCs, demonstrating their similar patterns of gene expression to the human ASCs, and providing additional evidence that the feline ASCs are representative of undifferentiated phenotype (Fig. 7). The variable gene expression patterns for the human and feline ASCs was highlighted by the fact that some human and feline ASC were clustered closer together than human to human or feline to feline ASCs. In addition, one undifferentiated human ASC line (hu-2) and one feline uninduced ASC line (fel-2) were more closely related to adipo-induced hASCs than to noninduced human and feline ASCs (Fig. 7).

\section{Discussion}

Clinical trials with cell therapies are increasingly taking advantage of companion animals with naturally occurring diseases as relevant, surrogate models to support novel human investigational drug applications (IND) and veterinary investigational new animal drug applications (INAD) $[19,20,30,60]$. Cats are a particularly important translational model for a number of diseases that are similar in cats and humans, including FIV (HIV) [61], T cell-mediated oral mucosa inflammation [24], chronic renal failure [29], asthma [25], chronic enteropathy [26], and osteoarthritis. The goal of this work was to profile feline ASCs and directly compare their phenotypic, cellular, and immunomodulatory profiles with human ASCs to deepen our understanding of MSC-based therapies as we move towards mechanismof-action studies in animals and people. We found that feline ASCs, like human ASCs, can be defined as MSCs based on defined criteria (surface phenotype, differentiation potential, morphology, doubling time, normal karyotype) and that their transcriptome clusters closely with uninduced (undifferentiated) human ASCs. Feline ASCs inhibit mitogen-activated T-cell proliferation and their profile of secreted immunomodulatory mediators closely mimics that of human ASCs, dominated by IDO, $\mathrm{PGE}_{2}$, TGF $\beta$, IL-6, and IL-8. Feline ASCs are highly activated and functional in the presence of the proinflammatory cytokines, IFN $\gamma$ and TNF $\alpha$, and, like human [6] and canine ASCs [12], their regulation of IFNY is complex and likely dictated by at least two mechanisms, depending on whether or not the ASCs are in direct contact with activated PBMCs.

The data we generated from human ASCs largely mimicked data from studies that either compared human ASCs with MSCs from other sources, especially bone marrow, or studies that determined the immunomodulatory phenotype of human ASCs. Similar to others, we found that ASCs were able to inhibit activated T-cell proliferation with or without direct ASC-T cell contact $[62,63]$; however, we also found that this inhibition was 

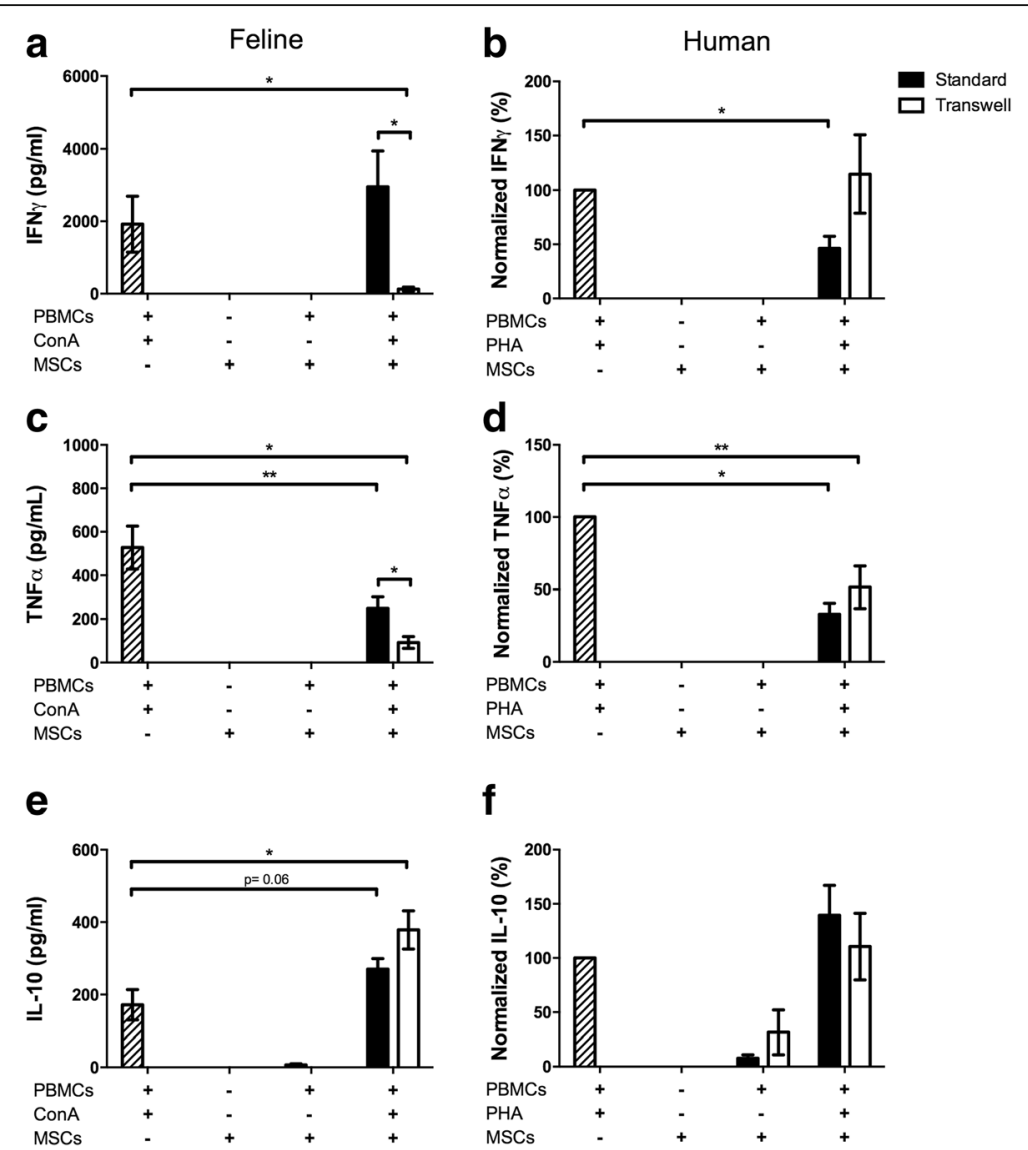

Fig. 5 Regulation of inflammatory mediators by human and feline ASCs differs. Feline ASCs in the presence of proliferating lymphocytes do not inhibit production of interferon gamma (IFNY). Removal of direct contact between ASCs and stimulated peripheral blood mononuclear cells (PBMCS) led to a significant reduction in IFNy production (a). Human ASCs in contact with PBMCs stimulated with leucoagglutinin (PHA) inhibit production of IFNy. However, when contact with activated PBMCs is removed, inhibition of IFNy does not occur (b). Feline ASCs inhibit production of tumor necrosis factor alpha ( $T N F a$ ) with or without contact, with the transwell condition inhibiting production of the mediator to a greater extent (c). Human ASCs inhibit production of TNFa regardless of contact with proliferating lymphocytes (d). Production of interleukin-10 (IL-10) in feline ASC lymphocyte co-cultures increased significantly without contact and was also increased with contact $(P=0.06)$ (e). No alterations in IL-10 production were observed by activated human ASCS (f). Data presented as mean and standard error. ${ }^{*} P<0.05,{ }^{* *} P<0.01,{ }^{* * *} P<0.001$. ConA concanavalin A, MSC mesenchymal stem cell

more marked when ASCs were in contact with activated cells. MSC-immune cell contact, especially in the context of both IFNY and TNF $\alpha$, has been shown to upregulate PD-1, VCAM-1, and ICAM-1 and this contact can then augment the production of soluble mediators, notably IDO $[7,21,64]$. Our data are also aligned with data from fetal membrane, or decidual, MSCs that also inhibit lymphocyte proliferation more profoundly in the presence of MSC-immune cell contact $[64,65]$. Contact-dependent inhibition of immune cell function is thought to be more important for local immunosuppression [65]. In the absence of cell-cell contact, human ASCs were unable to inhibit IFN $\gamma$ secretion and IL-8 production was decreased.

Unlike human and other veterinary species studied to date $[11,35]$, feline ASCs expanded in standard culture conditions do not proliferate robustly in vitro after passage 5 or $6[31,54]$. This is in spite of the fact that, similar to horses [35] and humans [66], adipose tissue is still the tissue of choice for feline MSC therapy due to the ease of collection, tissue abundance, and faster growth kinetics [53]. The most likely consideration for this poor, late-passage proliferation is inadequate cell culture condition optimization. This phenomenon is independent of feline foamy virus (FFV) infection as it occurs in ASC lines from SPF cats as well as client-owned cats free of FFV infection [31]. Our group has not investigated cell culture optimization with media supplementation of growth factors, increased FBS concentration, or cytokine supplementation; however, optimization would likely improve growth kinetics. Creating working cell banks of autologous or allogeneic ASCs at passage 1 and expanding to doses of $5 \times 10^{6}$ cells $/ \mathrm{kg}$ (passages 2 or 3 ) for clinical 
a

\begin{tabular}{|c|c|c|c|}
\hline Identifier & Feline ASC 1 & Feline ASC 2 & Feline ASC 3 \\
\hline Feline ASC 1 & 1.00000 & 0.85239 & 0.97444 \\
\hline Feline ASC 2 & 0.85239 & 1.00000 & 0.89059 \\
\hline Feline ASC 3 & 0.97444 & 0.89059 & 1.00000 \\
\hline
\end{tabular}

b

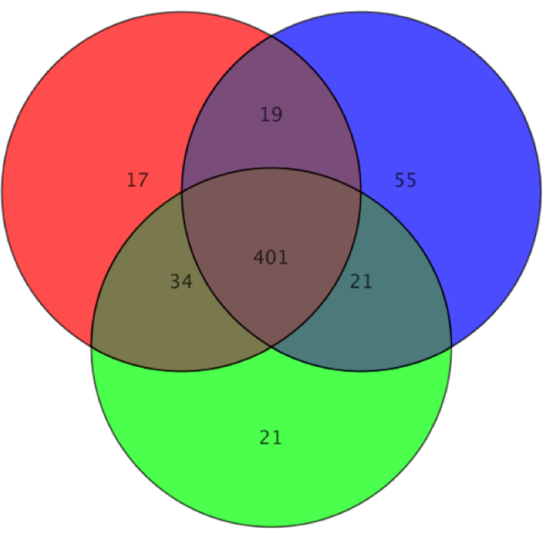

C

Gene Count

$\begin{array}{llllll}0 & 10 & 20 & 30 & 40 & 50\end{array}$

regulation of programmed cell death

regulation of cell proliferation

cell motion

negative regulation of apoptosis

response to hormone stimulus

anti-apoptosis

regulation of phosphate metabolic process

vasculature development

Oxidative phosphorylation

ECM-receptor interaction

response to oxidative stress

regulation of cell migration

는 regulation of cell morphogenesis

Integrin cell surface interactions

cell-matrix adhesion

ossification

ribonucleoside triphosphate metabolic process

bone development

regulation of neuron differentiation

oxidative phosphorylation

Signaling by Wnt

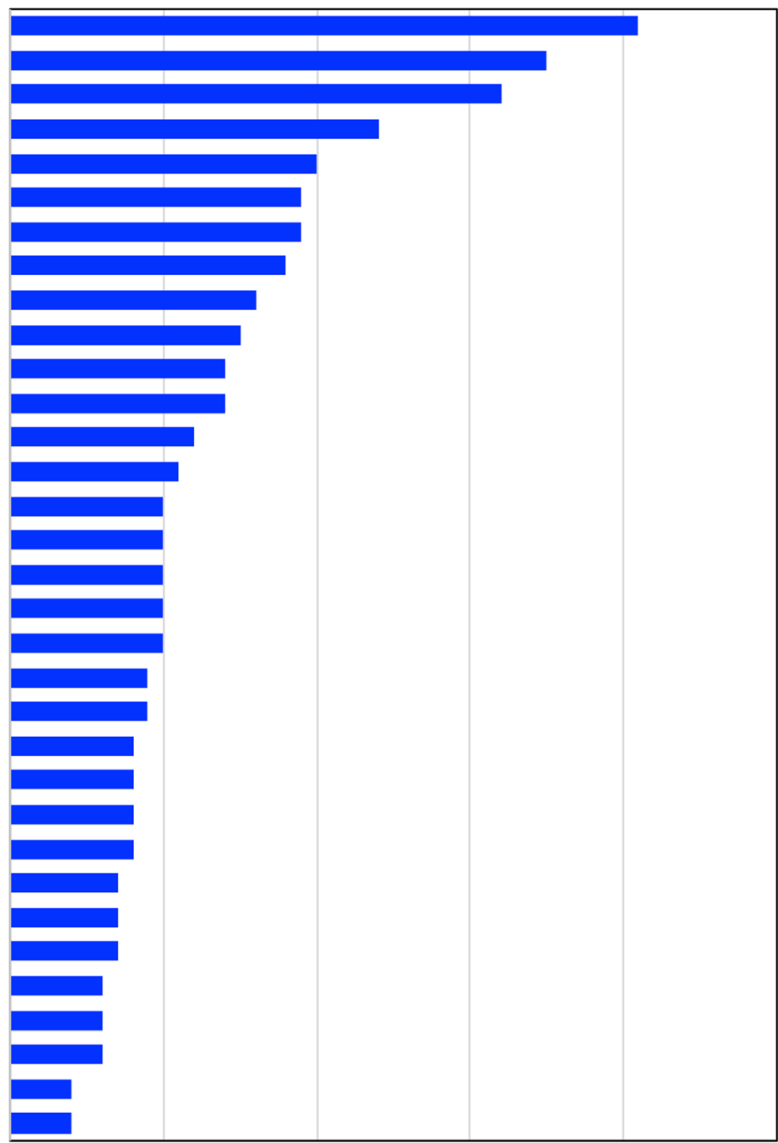

regulation of neuron projection development

cholesterol metabolic process

sterol metabolic process

ATP metabolic process

regulation of angiogenesis

integrin-mediated signaling pathway

regulation of cell morphogenesis involved in differentiation

regulation of endothelial cell proliferation

cell junction assembly

mTOR signaling pathway

sterol biosynthetic process

Pentose phosphate pathway

Fig. 6 (See legend on next page.) 
(See figure on previous page.)

Fig. 6 Transcriptome analysis reveals similarities between human and feline adipose-derived mesenchymal stem cells (ASCs) at the molecular level. Total RNA was isolated from undifferentiated feline ASC primary cultures established from three different cats. Correlation coefficients (Pearson $r$ ) show the relatedness of the different feline ASC cultures as determined by pair-wise correlation analysis of the gene-level FPKM data (a). Substantial similarity of the feline ASC lines is demonstrated by the Venn diagram, which depicts a greater than $\geq 87 \%$ overlap in gene expression profiles (401 genes) based on all genes exhibiting a high level of expression ( $\geq 100$ FPKM) (b). Functional analysis reveals prominent biological processes in feline MSCs. Gene annotation-enrichment analysis of the most highly expressed genes ( $\geq 100$ FPKM) in common to the three ASC preparations was performed. The gene ontology and pathway annotations (biological processes and pathways) specifically enriched within this gene list were filtered for statistical significance (Fisher Exact $P$ value $\leq 0.1$ ), and selected, representative categories presented (c)

use is readily achieved given the high number of ASCs obtained from small feline fat samples even without culture optimization.

MSCs derived from different tissues can vary substantially in size; for example, equine cord blood-derived MSCs are much larger than equine ASCs [67]. In this study, we found that ASCs in humans and cats differ in size, with feline ASCs being much smaller than human
ASCs. Cell size differences are likely to be irrelevant for basic biological functions; however, recognizing cell size differences may inform species-specific tissue engineering protocols and scaffold features [68]. MSC size has also been implicated in determining pulmonary entrapment after intravascular cell administration [69].

The key mediators secreted by human and feline ASCs were similar. We did not attempt to compare absolute

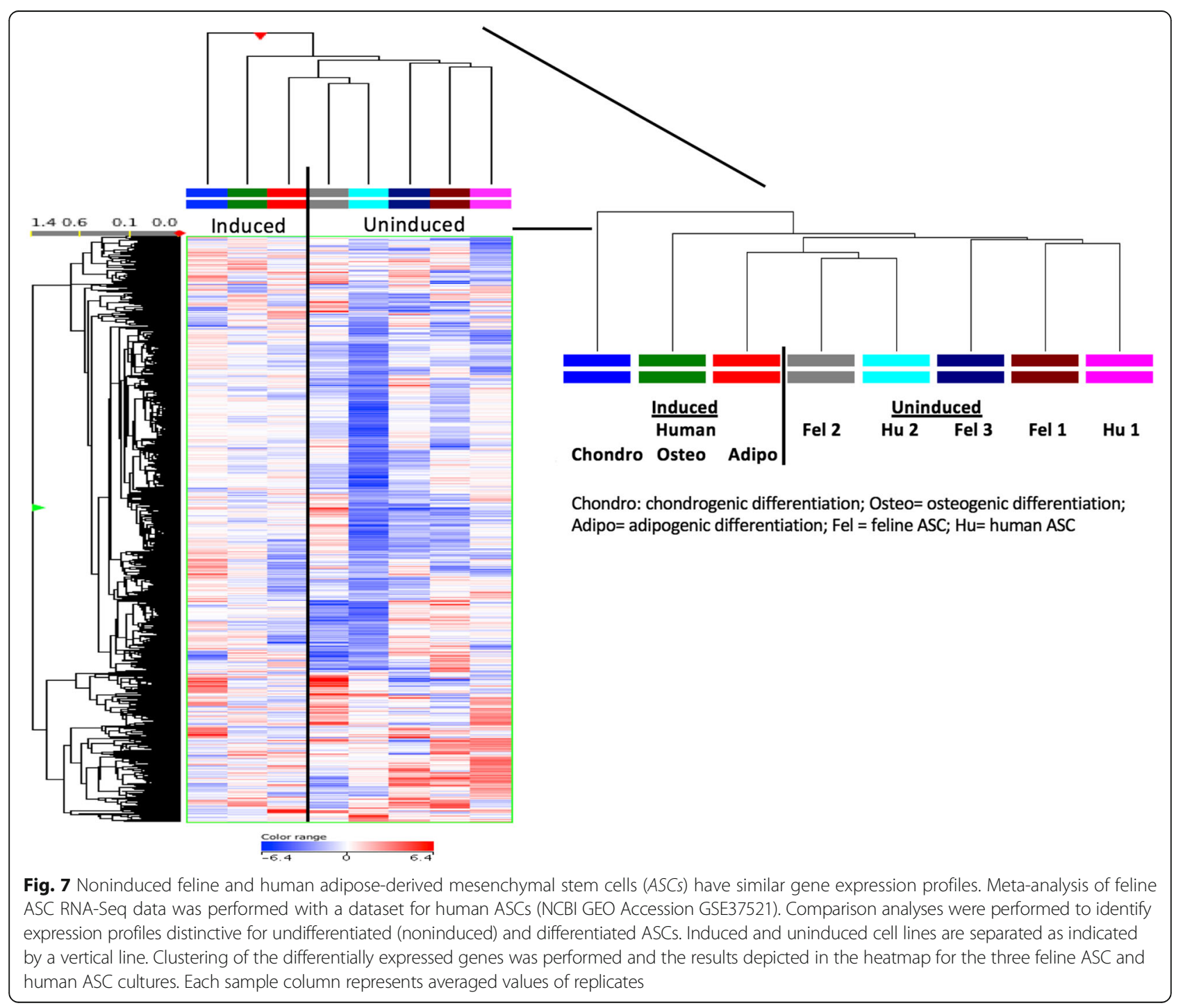


concentrations of secreted mediators as the mitogens selected (ConA and PHA) were different, the ELISA kits were different, and the degree of stimulation varied in the assays. Both PHA and ConA are nonspecific, potent T-cell mitogens. Mitogen selection and concentration was based on our early data examining proliferation kinetics and degree of activation as well as other published data in cats and humans [36-40]. Regardless, a few patterns are of interest. TGF $\beta 1$, VEGF and, to a lesser extent, $\mathrm{PGE}_{2}$ were the only mediators secreted to a measurable level by feline and human ASCs at baseline with no activation. The constitutive secretion of TGF $\beta 1$ concurs with previous findings in human [6, 7], equine [14], and canine [12] ASCs. TGF $\beta 1$ is involved in immune regulation by and differentiation of Foxp $^{+}$regulatory T cells and Th17 cells, and may play an important part in MSC immunomodulation although it is not involved in the inhibition of lymphocyte proliferation $[7,12,70]$. Interestingly, VEGF secretion was not increased after mitogen stimulation in human ASCs; however, VEGF secretion did increase after feline ASC activation. It may be that VEGF secretion in human ASCs is more sensitive to hypoxic signals rather than T-cell mitogens [71].

There were a number of differences in how feline and human ASCs inhibited lymphocyte proliferation and in their secretion profiles, with and without PBMC contact. These data suggest that there are multiple different mechanisms by which human and feline ASCs regulate inflammatory (most notably IFN $\gamma$ ) and regulatory (IL-10) mediator secretion by activated PBMCs, one dependent on cell contact and one primarily mediated by soluble factors. Also, $\mathrm{PGE}_{2}$ secretion was markedly diminished in the absence of direct cell-cell contact for cats. Data from our in vivo studies suggest that induction of $\mathrm{T}$ regulatory cells may be important as a mechanism by which MSCs cure oral inflammatory disease in cats [24]. T regulatory cells classically require cell-cell contact to function; however, many soluble mediators, including $\mathrm{PGE}_{2}$, TGF $\beta 1$, and IL-10, can also play a role in the induction of regulatory T cells [72, 73]. Deciphering these mechanisms is critical as, although both cell-cell contact and soluble mediator production are likely important in vivo, there is at least one condition under which IFN $\gamma$ secretion is not decreased. Sustained secretion of IFN $\gamma$ may have important implications for particular clinical applications as IFNY stimulates MSCs, derived from a number of tissues, to produce IDO, TGF $\beta$, and HGF, to increase cell-cell signaling via the upregulation of PD-L1 and ICAM-1, and to generate regulatory $\mathrm{CD}^{+} \mathrm{T}$ cells $[21,62,64,65,74-76]$. These data are in agreement with data from our in vivo study where two cats with severe, chronic, oral inflammation that fully responded to ASC therapy (complete, sustained disease resolution) did so in the context of high serum concentrations of IFN $\gamma$ [24].
Our findings suggest that uninduced feline ASCs are highly similar to human ASCs in their basic morphology, phenotype, and transcriptome. The goal of the transcriptome analysis was to determine the similarity of feline ASCs to human ASCs at the molecular level. As such, we focused the analysis on the expression of those genes that are highly relevant to MSC biology and did not compare the relatedness of culture-expanded feline ASCs to somatic feline tissues. It is likely that a number of feline ASC-expressed genes are shared across different feline tissues. Inclusion of biological controls (feline somatic tissues) would be needed to fully determine the stem-cell specificity of these data. Interestingly, the RNA-Seq data from one human ASC line, induced towards adipogenesis, was more closely aligned to one human and one feline ASC line that were uninduced. The origin of our MSCs from adipose tissue may recapitulate ASCs induced to differentiate along the adipose lineage more closely than those induced to differentiate towards bone or cartilage.

In summary, the activation of feline ASCs potentiates the secretion of a panel of immunomodulatory mediators that is comparable to human ASCs and human fetal decidual stem cells with one end result of decreasing lymphocyte proliferation. These data provide additional rationale for the use of naturally occurring diseases in cats as appropriate surrogate models for human regenerative medicine trials with MSCs when the diseases are also shown to be comparable. These data also provide the first published immunomodulatory (secretion) and transcriptome profile of feline ASCs from which further mechanism-of-action studies can result.

\section{Conclusion}

These data provide the first comprehensive side-by-side evaluation of human and feline ASCs including phenotype, immunomodulatory profile, and transcriptome. Findings suggest that feline ASCs are multipotent mesenchymal stem cells that, when activated by IFN $\gamma$, modulate lymphocyte proliferation using soluble mediators that mirror the human ASC secretion pattern. Transcriptome analysis revealed similar gene expression profiles to uninduced human ASCs and set the stage for deeper investigations using cats as surrogate models for human cell therapy-based clinical trials.

\section{Additional files}

Additional file 1: Figure S1. Representative karyotypes of feline and human ASCs. Both feline (A, B) and human (C, D) ASCs have a normal karyotype. (TIFF $19104 \mathrm{~kb}$ )

Additional file 2: Figure S2. Transcriptome analysis of ASCs. Full dataset of ASC gene expression profile. RNA-Seq analysis was performed on total mRNA prepared from three separate feline noninduced ASC 
culture preparations (passage 3), followed by data analysis with a standard HISAT-Cufflinks pipeline to yield gene expression values expressed as FPKM. (XLSX $1420 \mathrm{~kb})$

\section{Abbreviations}

ASC: Adipose-derived mesenchymal stem cell; BrdU: 5-Bromo-29deoxyuridine; ConA: Concanavalin A; ELISA: Enzyme-linked immunosorbent assay; FBS: Fetal bovine serum; FFV: Feline foamy virus; GSR: Genomics Shared Resource; IDO: Indoleamine 2,3 dioxygenase; IFN: interferon; IL: Interleukin; IND: Investigational drug applications; LSA: Lymphocyte suppression assay; MEM: Minimum essential medium; MSC: Mesenchymal stem cell; PBMC: peripheral blood monocular cell; PBS: Phosphate-buffered saline; PGE 2: Prostaglandin E2; PHA: Leucoagglutinin; SPF: Specific pathogenfree; TGF: Transforming growth factor; TNF: Tumor necrosis factor; UCD: University of California, Davis; VEGF: Vascular endothelial growth factor

\section{Acknowledgements}

The authors thank Catherine Nacey (karyotyping), Megan Badgley (sample acquisition and technical support), and Ryan R. Davis and Stephenie Y. Liu (UCDCCC Genomics Shared Resource, Department of Pathology and Laboratory Medicine) for their expert technical assistance for the RNA-Seq analysis studies. The UC Davis Comprehensive Cancer Center Genomics Shared Resource is supported by Cancer Center Support Grant P30CA093373 from the $\mathrm{NCl}$

\section{Funding}

This study was supported by the National Institutes of Health grant 1R21DE024711-01 (DLB), by the Department of Dermatology, School of Medicine, University of California, Davis (NF and WJM), and by a generous gift from Mr. Dick and Carolyn Randall (DLB). KCC was supported by a California Institute of Regenerative Medicine, Stem Cell Training Grant TB1-01175.

\section{Availability of data and material}

All nontranscriptomic datasets used and/or analyzed during the current study are available from the corresponding author on reasonable request. All transcriptome data generated during this study are included in this published article (and its supplementary additional files). The datasets generated and/or analyzed during the current study are available in the NCBI GEO Datasets (Accession number: GSE94773.

\section{Author's contributions}

KCC: collection and assembly of data, data analysis, and manuscript writing. FAF: conception and design, provision of study material, collection and assembly of data, data analysis and interpretation, manuscript writing, and review of manuscript. EMK: collection and assembly of data, data analysis and interpretation, and review of manuscript. NJW: collection and assembly of data, and review of manuscript. BA: provision of study material, and review of manuscript. CGT: collection and assembly of data, and review of manuscript. HD: collection and assembly of data, and review of manuscript. AC: collection and assembly of data, and review of manuscript. AK: collection and assembly of data, and review of manuscript. LM: collection and assembly of data, and review of manuscript. WJM: conception and design, financial support, and final approval of manuscript. NF: conception and design, and final approval of manuscript. DLB: conception and design, data analysis, financial support, manuscript writing, and final approval of manuscript.

\section{Competing interests}

The authors declare that they have no competing interests.

\section{Consent for publication}

All authors have seen and approved the content of this manuscript and have consented to its publication.

\section{Ethics approval and consent to participate}

For human tissues, obtaining adipose tissue from discarded material from surgeries was approved by the Institutional Review Board, UCD, protocol number 258314-8. For all human tissues collected, informed patient consent forms were obtained. For feline tissues, fat collection was conducted according to a protocol (\#18422) approved by the Institutional Animal Care and Use Committee, and the Clinical Trials Review Board, UCD in 2014. All owners of client-owned cats signed an informed consent form.

\section{Publisher's Note}

Springer Nature remains neutral with regard to jurisdictional claims in published maps and institutional affiliations.

\section{Author details}

${ }^{1}$ Veterinary Institute for Regenerative Cures and Department of Pathology, Microbiology and Immunology, University of California, Davis, CA 95816, USA. ${ }^{2}$ Institute for Regenerative Cures and Department of Cell Biology and Human Anatomy, University of California, Davis, CA 95816, USA. ${ }^{3}$ Department of Surgical and Radiological Sciences, School of Veterinary Medicine, University of California, Davis, CA 95816, USA. ${ }^{4}$ Department of Biochemistry and Molecular Medicine, University of California, Davis, CA 95816, USA.

${ }^{5}$ Department of Dermatology, School of Medicine, University of California, Davis, CA 95816, USA.

Received: 29 November 2016 Revised: 10 February 2017 Accepted: 3 March 2017 Published online: 20 March 2017

\section{References}

1. Dominici M, Le Blanc K, Mueller I, et al. Minimal criteria for defining multipotent mesenchymal stromal cells. The International Society for Cellular Therapy position statement. Cytotherapy. 2006;8:315-7.

2. Gimble JM, Katz AJ, Bunnell BA. Adipose-derived stem cells for regenerative medicine. Circ Res. 2007;100:1249-60.

3. Ivanova-Todorova E, Bochev I, Mourdjeva M, et al. Adipose tissue-derived mesenchymal stem cells are more potent suppressors of dendritic cells differentiation compared to bone marrow-derived mesenchymal stem cells. Immunol Lett. 2009;126:37-42.

4. Jansen $\mathrm{BJ}$, Gilissen $\mathrm{C}$, Roelofs $\mathrm{H}_{\text {, et }}$ al. Functional differences between mesenchymal stem cell populations are reflected by their transcriptome. Stem Cells Dev. 2009;19:481-90.

5. Keyser KA, Beagles KE, Kiem HP. Comparison of mesenchymal stem cells from different tissues to suppress T-cell activation. Cell Transplant. 2007;16:555-62.

6. Melief SM, Zwaginga JJ, Fibbe WE, et al. Adipose tissue-derived multipotent stromal cells have a higher immunomodulatory capacity than their bone marrow-derived counterparts. Stem Cells Transl Med. 2013;2:455-63.

7. Yoo KH, Jang IK, Lee MW, et al. Comparison of immunomodulatory properties of mesenchymal stem cells derived from adult human tissues. Cell Immunol. 2009;259:150-6.

8. Glenn JD, Whartenby KA. Mesenchymal stem cells: emerging mechanisms of immunomodulation and therapy. World J Stem Cells. 2014;6:526-39.

9. Le Blanc K, Davies LC. Mesenchymal stromal cells and the innate immune response. Immunol Lett. 2015;168(2):140-46.

10. Carrade DD, Borjesson DL. Immunomodulation by mesenchymal stem cells in veterinary species. Comp Med. 2013;63:207-17.

11. Clark KC, Kol A, Shahbenderian S, et al. Canine and equine mesenchymal stem cells grown in serum free media have altered immunophenotype. Stem Cell Rev. 2016;12:245-56.

12. Kang JW, Kang KS, Koo HC, et al. Soluble factor-mediated immunomodulatory effects of canine adipose tissue-derived mesenchymal stem cells. Stem Cells Dev. 2008;17:681-93.

13. Kol A, Foutouhi S, Walker NJ, et al. Gastrointestinal microbes interact with canine adipose-derived mesenchymal stem cells in vitro and enhance immunomodulatory functions. Stem Cells Dev. 2014;23:1831-43.

14. Carrade DD, Lame MW, Kent MS, et al. Comparative analysis of the immunomodulatory properties of equine adult-derived mesenchymal stem cells. Cell Med. 2012:4:1-11.

15. Cahill EF, Sax T, Hartmann I, et al. Mesenchymal stromal cells protect endothelial cells from cytotoxic T lymphocyte induced lysis. Scand J Immunol. 2016;84(3):158-64.

16. Ciccocioppo R, Cangemi GC, Kruzliak P, et al. Ex vivo immunosuppressive effects of mesenchymal stem cells on Crohn's disease mucosal T cells are largely dependent on indoleamine 2,3-dioxygenase activity and cell-cell contact. Stem Cell Res Ther. 2015;6:137. 
17. Franquesa M, Mensah FK, Huizinga R, et al. Human adipose tissue-derived mesenchymal stem cells abrogate plasmablast formation and induce regulatory B cells independently of T helper cells. Stem Cells. 2015;33:880-91.

18. Galipeau J, Krampera M, Barrett J, et al. International Society for Cellular Therapy perspective on immune functional assays for mesenchymal stromal cells as potency release criterion for advanced phase clinical trials. Cytotherapy. 2016;18:151-9.

19. Lairmore MD, Khanna C. Naturally occurring diseases in animals: contributions to translational medicine. ILAR J. 2014;55:1-3.

20. Kol A, Arzi B, Athanasiou KA, et al. Companion animals: translational scientist's new best friends. Sci Transl Med. 2015;7:308ps321.

21. Ren G, Su J, Zhang L, et al. Species variation in the mechanisms of mesenchymal stem cell-mediated immunosuppression. Stem Cells. 2009;27:1954-62.

22. Strioga M, Pasukoniene $V$, Characiejus D. $C D 8^{+} C D 28^{-}$and $C D 8^{+} C D 57^{+} T$ cells and their role in health and disease. Immunology. 2011;134:17-32.

23. Vallejo AN. CD28 extinction in human T cells: altered functions and the program of T-cell senescence. Immunol Rev. 2005;205:158-69.

24. Arzi B, Mills-Ko E, Verstraete FJ, et al. Therapeutic efficacy of fresh, autologous mesenchymal stem cells for severe refractory gingivostomatitis in cats. Stem Cells Transl Med. 2016;5:75-86.

25. Trzil JE, Masseau I, Webb TL, et al. Intravenous adipose-derived mesenchymal stem cell therapy for the treatment of feline asthma: a pilot study. J Feline Med Surg. 2015;18(12):981-90.

26. Webb TL, Webb CB. Stem cell therapy in cats with chronic enteropathy: a proof-of-concept study. J Feline Med Surg. 2015;17:901-8.

27. Bascones-Martinez A, Garcia-Garcia V, Meurman JH, et al. Immune-mediated diseases: what can be found in the oral cavity? Int J Dermatol. 2015;54:258-70.

28. Harley R, Gruffydd-Jones TJ, Day MJ. Immunohistochemical characterization of oral mucosal lesions in cats with chronic gingivostomatitis. J Comp Pathol. 2011;144:239-50.

29. Quimby JM, Webb TL, Randall E, et al. Assessment of intravenous adiposederived allogeneic mesenchymal stem cells for the treatment of feline chronic kidney disease: a randomized, placebo-controlled clinical trial in eight cats. J Feline Med Surg. 2016;18:165-71.

30. Hoffman AM, Dow SW. Concise review: stem cell trials using companion animal disease models. Stem Cells. 2016;34:1709-29.

31. Arzi B, Kol A, Murphy $B$, et al. Feline foamy virus adversely affects feline mesenchymal stem cell culture and expansion: implications for animal model development. Stem Cells Dev. 2015;24:814-23.

32. Cary WA, Hori CN, Pham MT, et al. Efficient generation of induced pluripotent stem and neural progenitor cells from acutely harvested dura mater obtained during ventriculoperitoneal shunt surgery. World Neurosurg. 2015:84:1256-66. e1251.

33. Beegle J, Lakatos K, Kalomoiris S, et al. Hypoxic preconditioning of mesenchymal stromal cells induces metabolic changes, enhances survival, and promotes cell retention in vivo. Stem Cells. 2015;33:1818-28.

34. Martin DR, Cox NR, Hathcock TL, et al. Isolation and characterization of multipotential mesenchymal stem cells from feline bone marrow. Exp Hematol. 2002;30:879-86.

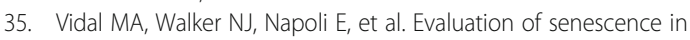
mesenchymal stem cells isolated from equine bone marrow, adipose tissue, and umbilical cord tissue. Stem Cells Dev. 2012;21:273-83.

36. Rojko JL, Hoover EA, Finn BL, et al. Characterization and mitogenesis of feline lymphocyte populations. Int Arch Allergy Appl Immunol. 1982;68:226-32.

37. Choi IS, Hokanson R, Collisson EW. Anti-feline immunodeficiency virus (FIV) soluble factor(s) produced from antigen-stimulated feline CD8(+) T lymphocytes suppresses FIV replication. J Virol. 2000;74:676-83.

38. Miller MM, Petty CS, Tompkins MB, et al. CD4 ${ }^{+} \mathrm{CD} 25^{+} \mathrm{T}$ regulatory cells activated during feline immunodeficiency virus infection convert $\mathrm{T}$ helper cells into functional suppressors through a membrane-bound TGF $\beta / G A R P$ mediated mechanism. Virol J. 2014;11:7.

39. Azzolina LS, Stevanoni G, Tommasi M, et al. Phenotypic analysis of human peripheral blood lymphocytes by automatic sampling flow cytometry after stimulation with mitogens or allogeneic cells. Res Clin Lab. 1990;20:209-16.

40. Miller K. The stimulation of human B and T lymphocytes by various lectins. Immunobiology. 1983;165:132-46.

41. Arata S, Ohmi A, Mizukoshi F, et al. Urinary transforming growth factorbeta1 in feline chronic renal failure. J Vet Med Sci. 2005;67:1253-5.

42. Koga L, Kobayashi Y, Yazawa M, et al. Nucleotide sequence and expression of the feline vascular endothelial growth factor. J Vet Med Sci. 2002;64:453-6.
43. Wypij JM, Fan TM, Fredrickson RL, et al. In vivo and in vitro efficacy of zoledronate for treating oral squamous cell carcinoma in cats. J Vet Intern Med. 2008;22:158-63.

44. Morchón R, Roca F, López-Belmonte J, et al. Changes in the levels of eicosanoids in cats naturally and experimentally infected with Dirofilaria immitis. Vet Parasitol. 2007;147:271-5.

45. McCord JL, Hayes SG, Kaufman MP. PPADS does not block contractioninduced prostaglandin E2 synthesis in cat skeletal muscle. Am J Physiol Heart Circ Physiol. 2008;295:H2043-5.

46. Bentley DR, Balasubramanian S, Swerdlow HP, et al. Accurate whole human genome sequencing using reversible terminator chemistry. Nature. 2008;456:53-9.

47. Kim D, Langmead B, Salzberg SL. HISAT: a fast spliced aligner with low memory requirements. Nat Methods. 2015;12:357-60.

48. Trapnell C, Williams BA, Pertea G, et al. Transcript assembly and quantification by RNA-Seq reveals unannotated transcripts and isoform switching during cell differentiation. Nat Biotechnol. 2010;28:511-5.

49. da Huang W, Sherman BT, Lempicki RA. Systematic and integrative analysis of large gene lists using DAVID bioinformatics resources. Nat Protoc. 2009;4:44-57.

50. da Huang W, Sherman BT, Lempicki RA. Bioinformatics enrichment tools: paths toward the comprehensive functional analysis of large gene lists. Nucleic Acids Res. 2009;37:1-13.

51. Jääger $K$, Islam $S$, Zajac $P$, et al. RNA-Seq analysis reveals different dynamics of differentiation of human dermis- and adipose-derived stromal stem cells. PLoS One. 2012;7:e38833.

52. Kim HR, Lee J, Byeon JS, et al. Extensive characterization of feline intraabdominal adipose-derived mesenchymal stem cells. J Vet Sci. 2016. Published online: July 25, 2016.

53. Webb TL, Quimby JM, Dow SW. In vitro comparison of feline bone marrowderived and adipose tissue-derived mesenchymal stem cells. J Feline Med Surg. 2012;14:165-8.

54. Kono S, Kazama T, Kano K, et al. Phenotypic and functional properties of feline dedifferentiated fat cells and adipose-derived stem cells. Vet J. 2014;199:88-96.

55. Mumaw JL, Schmiedt CW, Breidling S, et al. Feline mesenchymal stem cells and supernatant inhibit reactive oxygen species production in cultured feline neutrophils. Res Vet Sci. 2015;103:60-9.

56. Parys M, Nelson N, Koehl K, et al. Safety of intraperitoneal injection of adipose tissue-derived autologous mesenchymal stem cells in cats. J Vet Intern Med. 2016;30:157-63.

57. Quimby JM, Webb TL, Habenicht LM, et al. Safety and efficacy of intravenous infusion of allogeneic cryopreserved mesenchymal stem cells for treatment of chronic kidney disease in cats: results of three sequential pilot studies. Stem Cell Res Ther. 2013;4:48.

58. Groh ME, Maitra B, Szekely E, et al. Human mesenchymal stem cells require monocyte-mediated activation to suppress alloreactive T cells. Exp Hematol. 2005;33:928-34

59. Screven R, Kenyon E, Myers MJ, et al. Immunophenotype and gene expression profile of mesenchymal stem cells derived from canine adipose tissue and bone marrow. Vet Immunol Immunopathol. 2014;161:21-31.

60. Grimm D. From bark to bedside. Science. 2016;353:638-40.

61. Miller MM, Fogle JE, Ross $P$, et al. Feline glycoprotein A repetitions predominant anchors transforming growth factor beta on the surface of activated CD4(+)CD25(+) regulatory T cells and mediates AIDS lentivirusinduced T cell immunodeficiency. AIDS Res Hum Retroviruses. 2013;29:641-51.

62. Krampera M, Cosmi L, Angeli $\mathrm{R}$, et al. Role for interferon-gamma in the immunomodulatory activity of human bone marrow mesenchymal stem cells. Stem Cells. 2006;24:386-98.

63. Rasmusson I, Ringden O, Sundberg B, et al. Mesenchymal stem cells inhibit the formation of cytotoxic T lymphocytes, but not activated cytotoxic $T$ lymphocytes or natural killer cells. Transplantation. 2003;76:1208-13.

64. Karlsson H, Erkers T, Nava S, et al. Stromal cells from term fetal membrane are highly suppressive in allogeneic settings in vitro. Clin Exp Immunol. 2012;167:543-55.

65. Erkers T, Nava S, Yosef J, et al. Decidual stromal cells promote regulatory $T$ cells and suppress alloreactivity in a cell contact-dependent manner. Stem Cells Dev. 2013;22:2596-605.

66. Kern S, Eichler H, Stoeve J, et al. Comparative analysis of mesenchymal stem cells from bone marrow, umbilical cord blood, or adipose tissue. Stem Cells. 2006;24:1294-301. 
67. Toupadakis CA, Wong A, Genetos DC, et al. Comparison of the osteogenic potential of equine mesenchymal stem cells from bone marrow, adipose tissue, umbilical cord blood, and umbilical cord tissue. Am J Vet Res. 2010;71:1237-45.

68. Di Luca A, Ostrowska B, Lorenzo-Moldero I, et al. Gradients in pore size enhance the osteogenic differentiation of human mesenchymal stromal cells in three-dimensional scaffolds. Sci Rep. 2016;6:22898.

69. Campbell NG, Kaneko M, Shintani Y, et al. Cell size critically determines initial retention of bone marrow mononuclear cells in the heart after intracoronary injection: evidence from a rat model. PLoS One. 2016;11:e0158232.

70. Carrade Holt DD, Wood JA, Granick JL, et al. Equine mesenchymal stem cells inhibit T cell proliferation through different mechanisms depending on tissue source. Stem Cells Dev. 2014;23:1258-65.

71. Lakatos K, Kalomoiris S, Merkely B, et al. Mesenchymal stem cells respond to hypoxia by increasing diacylglycerols. J Cell Biochem. 2016;117:300-7.

72. Baratelli $F$, Lin $Y$, Zhu $L$, et al. Prostaglandin $E_{2}$ induces FOXP3 gene expression and T regulatory cell function in human CD4 T cells. J Immunol. 2005;175:1483-90.

73. Chen W, Jin W, Hardegen N, et al. Conversion of peripheral $C D 4^{+} C D 25^{-}$ naive $\mathrm{T}$ cells to $\mathrm{CD} 4^{+} \mathrm{CD} 25^{+}$regulatory $\mathrm{T}$ cells by TGF-beta induction of transcription factor Foxp3. J Exp Med. 2003;198:1875-86.

74. Myers L, Croft M, Kwon BS, et al. Peptide-specific CD8 T regulatory cells use IFN-gamma to elaborate TGF-beta-based suppression. J Immunol. 2005; 174:7625-32.

75. Niederkorn JY. Emerging concepts in $\mathrm{CD} 8^{+} \mathrm{T}$ regulatory cells. Curr Opin Immunol. 2008:20:327-31.

76. Ryan JM, Barry F, Murphy JM, et al. Interferon-gamma does not break, but promotes the immunosuppressive capacity of adult human mesenchymal stem cells. Clin Exp Immunol. 2007;149:353-63.

\section{Submit your next manuscript to BioMed Central and we will help you at every step:}

- We accept pre-submission inquiries

- Our selector tool helps you to find the most relevant journal

- We provide round the clock customer support

- Convenient online submission

- Thorough peer review

- Inclusion in PubMed and all major indexing services

- Maximum visibility for your research

Submit your manuscript at www.biomedcentral.com/submit 